\title{
Diversity of Monogononta rotifer species among standing waterbodies in northern Cambodia
}

\author{
Ratha SOR, ${ }^{1}$ Seanghun MEAS, ${ }^{*}{ }^{*}$ Ken K.Y. WONG, ${ }^{2}$ Malay MIN,,${ }^{2}$ Hendrik SEGERS ${ }^{3}$ \\ ${ }^{1}$ Centre for Biodiversity Conservation, Faculty of Science, Royal University of Phnom Penh, Blvd Confederation of Russia, 12000 \\ Phnom Penh, Cambodia; ${ }^{2}$ Department of Biology, Faculty of Science, Royal University of Phnom Penh, Blvd Confederation of Russia, \\ 12000 Phnom Penh, Cambodia; ${ }^{3}$ Royal Belgian Institute of Natural Sciences, Vautierstraat 29, 1000 Brussels, Belgium
}

\begin{abstract}
The incidence and abundance of Monogononta rotifer species were recorded from lakes and reservoirs in the upper part of the Cambodian Mekong River basin in April and November 2010. One hundred and seven species are reported, 25 of which are new records to Cambodia and 8 taxa were unidentifiable to species level. Species richness at the regional and local scale was not significantly different between habitat types or between seasons, whether it was estimated using incidence or abundance data. Comparison of incidence data also revealed no significant difference from species richness of ponds concurrently sampled in the same region. There appeared to be a high level of diversity among sites that could not be attributed to nestedness or to the 5 environmental variables measured. Each habitat type and season offered substantially different rotifer communities, with the proportion of unshared species between sample sets ranging from 14-49\%. Non-metric multidimensional scaling and PERMANOVA analyses also revealed clustering and significant differences among sample sets based on habitat type and season. Therefore, each habitat type and season contributed to the overall rotifer biodiversity. When the incidence data from this study are combined with those in previously reported studies, the overall species richness estimate for Cambodia is 403 species (95\% CI=386-432) and the number of species records has reached 306.
\end{abstract}

Key words: Biodiversity, freshwater biology, invertebrates, species records, species richness.

Received: April 2014. Accepted: August 2014.

\section{INTRODUCTION}

In Southeast Asia, Monogononta rotifers are well-studied in Thailand with 347 confirmed species reported in 2005 (Savatenalinton and Segers, 2005), which has been recently updated to 398 in 2013 (Sa-Ardrit et al., 2013). Rotifers of other countries in the region could be considered poorly studied; e.g., Laotian fauna, 130 taxa (Segers and Sanoamuang, 2007); Philippino fauna, 115 taxa (Tuyor and Segers, 1999); Myanmar fauna, 100 taxa (Koste, 1990); and Brunei fauna, 2 taxa (Segers, 1994). Until recently Cambodian fauna was also categorized as information-scarce (Segers, 2001).

Knowledge of Cambodian rotifer fauna had not been developed for many years after the first 4 records by Bērzin̄š (1973). There was no other report until the 34 and 74 species records reported in the lower Mekong River basin from two successive surveys commissioned by the Mekong River Commission (Davidson et al., 2006; Vongsombath et al., 2009). Species records were extensively expanded by the 143 species found from different aquatic habitats by Meas and Sanoamuang (2010). Since 2010, new rotifer records from historical pond, rural ponds, lakes and reservoirs by Segers et al. (2010), Min et al. (2011) and Sor (2011) have increased Cambodian rotifer records to 240 species. A number of new rotifer species records, including new genus records, were found in the most recent study of permanent and seasonal wetlands (Min, 2013). Most of the habitats sampled in these studies were canals, rivers, ponds, floodplains and wetlands, while large standing waterbodies, such as lakes, represented only a small portion of the total and they were sampled only during the dry season to date.

The 10 sampling sites of this study constitute a subset of 50 aquatic sites in northern Cambodia that are being monitored in recent years to establish baseline data before the construction of hydropower dams upstream on the Mekong River and the Sesan River. The overall aim of the monitoring program is to identify and understand patterns in species richness and distribution before studying the impact of dam construction. The present paper provides a descriptive analysis of species occurrence in large standing water bodies (i.e., lakes and reservoirs), specifically on Monogononta rotifers in Cambodia, their species richness and diversity in the two habitat types in the dry and wet seasons. It further provides a comparison of species richness and diversity with small standing water bodies (i.e., ponds), which constituted another subset of sites sampled in the region during the same periods (Min et al., 2011; Chean and Meas, 2011). 


\section{METHODS}

\section{Data collection}

A total of forty rotifer samples were collected from 10 sites of large standing waterbodies in three provinces of the upper Cambodian Mekong River basin (Fig. 1). Five of the sites were lakes and the other five were artificial reservoirs, with the latter being distinguished by the presence of elevated embankments and/or weirs. Each site was sampled twice on two occasions (dry and wet season) to obtain a sample for determining species abundance data and a sample for species incidence data. The first collection was in the late dry season (25-30 April 2010) and the second was in the late wet season (7-12 November 2010). All samples were concentrated with 30-micrometer mesh plankton net, and immediately preserved by adding concentrated formaldehyde $(37-40 \%)$ to obtain a final con- centration of about $4 \%$. From each site on each occasion, one sample, concentrated from 15 tosses of the net (mouth diameter of $30 \mathrm{~cm}$ ) in different directions into the waterbody at distances of 7 to $10 \mathrm{~m}$, was used for identifying species to obtain incidence data. A second sample, from $100 \mathrm{~L}$ collected by pulling a 20-litre container 5 times, provided the 5 subsamples used for identifying and counting individuals to obtain species abundance data. The forty samples therefore consisted of 2 seasons $\times 2$ habitat types $\times 5$ sites $\times 2$ data purposes. Environmental variables measured at each sampled locality included water temperature, $\mathrm{pH}$, conductivity $(\mathrm{pH} / \mathrm{EC} / \mathrm{Temperature}$ Tester, model HI 98129, HANNA Instruments, Woonsocket, RI, USA), turbidity (ISO Portable Turbidity Meter, model HI 98713, HANNA Instruments), and dissolved oxygen (Dissolved Oxygen Meter, model HI 9146, HANNA Instruments). Rotifer specimens were identified to species under

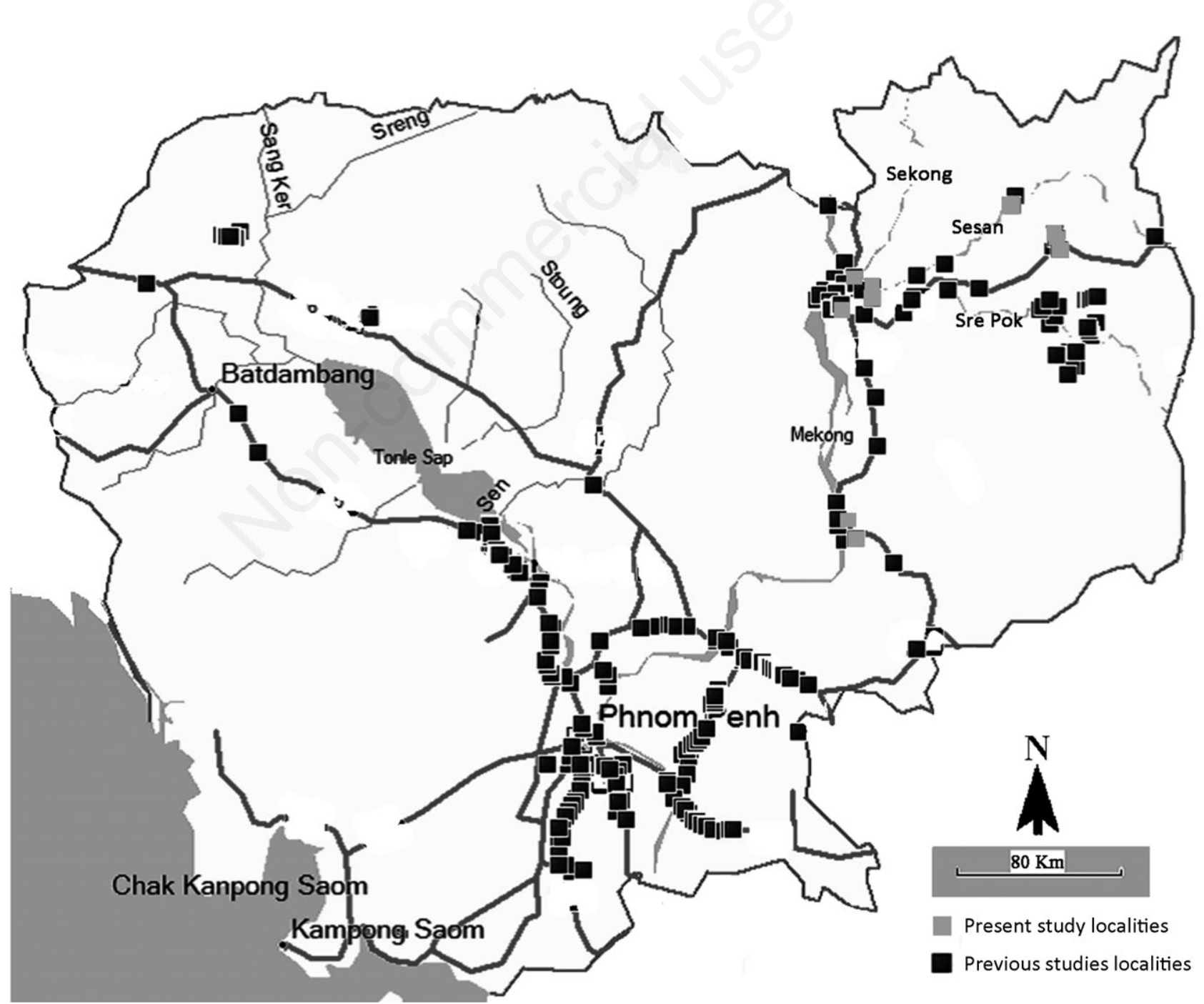

Fig. 1. Localities of present and previous studies. 
a compound microscope, using the keys reported by Koste (1978), Nogrady and Segers (2002), Nogrady et al. (1995), Segers (1995) and De Smet and Pourriot (1997). A digital camera fitted on an Olympus BX51 microscope was used to photograph rotifer specimens where appropriate. Species lists were then compared to previous records and to the annotated checklist of Segers (2007).

On the same field trips, 10 ponds (i.e., small standing waterbodies) were also sampled in the same region using exactly the same techniques. Only incidence data have been determined for these samples, and measurements of dissolved oxygen were missing for the wet season samples (Chean and Meas, 2011; Min et al., 2011). The data from these samples were compared to the results of this study.

\section{Species diversity}

Species richness (i.e., $\gamma$ diversity, $D_{\gamma}$ ) of different sample sets (all data, 20 samples; lakes, 10; reservoirs, 10; dry season, 10; wet season, 10) was estimated from the abundance and incidence data using the Chao 1 and Chao 2 estimators, respectively. The bias-corrected versions of the Chao 1 and Chao2 estimators calculated with SPADE v. 4 (Chao and Shen, 2006) were used in order to allow comparisons of different datasets because these versions can always be calculated; however, these versions assume that detection probabilities of all species are similar. Statistical differences between sample were recognised when there was no overlap in $95 \%$ confidence intervals (CI). The unidentifiable taxa were also compared and discussed. The overall Cambodian rotifer species richness was estimated by combining the present incidence data with those of Bērziñš (1973), Davidson et al. (2006), Vongsombath et al. (2009), Meas and Sanoamuang (2010), Prouch (2010), Segers et al. (2010), Min et al. (2011), Chean and Meas (2011), Meas and Sor (in press) and Min (2013).

Species count per sample was determined for each site, and the average for a sample set was used as an estimate of its $\alpha$ diversity $\left(D_{\alpha}\right)$. For each site, species abundance data were also used to determine dominance and Berger-Parker index using PAST v. 3 (Hammer et al., 2001) and to calculate rotifer density. Relevant pairs of sample sets were statistically compared using $t$-test, and also using paired $t$-test when comparing sites sampled in the two seasons, as the data showed no significant deviation $(\mathrm{P}>0.05)$ from normal distribution according to the Shapiro-Wilk W statistic and from equivalent variances according to the $\mathrm{F}$ test. For multi-sample comparisons, ANOVA was performed to ascertain the presence of statistic difference among samples with the homogeneity of variance confirmed using Levene's test, and when appropriate posthoc pairwise comparisons were conducted using the Tukey test. All calculations were performed using PAST v. 3 . $\beta$ diversity, $D_{\beta}$, was estimated using $D_{\gamma} / D_{\alpha}$ (Anderson et al., 2011). The role of nestedness in
$D_{\beta}$ was assessed using NODF v. 2 (Almeida-Neto and Ulrich, 2011). For this analysis, the species incidence matrix was randomised using fixed row and fixed column constraints (FF) or proportional row and proportional column constraints (PP) to generate 1000 random null matrices for comparison with the observed matrix. The Z-transformed NODF metric provided the standard effect size for comparison, and its P-value was used for statistical inference between the observed and expected matrices.

\section{Multivariate analysis of environmental variables}

Multivariate comparison of species composition of samples and their corresponding environmental variables was conducted using the strategy and procedure described by Clarke and Ainsworth (1993). Species abundance data were transformed using double square-root to reduce the effect of very common species on any patterns revealed by the analysis, the among sample similarity matrix was constructed using the Bray-Curtis coefficient that is not affected by the numerous occurrences of joint absences of species among sample pairs, and the dissimilarity coefficients for all sample pairs were ranked. A similar procedure was used to obtain 31 rank orders of the samples according to all 31 possible combinations of the 5 environmental variables. For the environmental variables, only the data for conductivity and turbidity were transformed using double square-root to achieve near normality of data, the data for all variables were subsequently normalised, and the among sample similarity matrix was constructed using Euclidean distances. Scatter plots of pairs of environmental variables, used also to assess the need for data transformation, did not reveal strongly correlated variable pairs (i.e., $\mathrm{r}^{2}>0.9$ ) that could be combined for the analysis. The rank order of biotic dissimilarity for the different samples was compared to each of the 31 rank orders of abiotic dissimilarity using the weighted Spearman rank correlation coefficient, $\rho_{\mathrm{w}}$, the values of which range from -1 to 1 . Similarity coefficient matrices, nonmetric multidimensional scaling (nMDS) and PERMANOVA were determined using PAST v. 3. nMDS was used to visualise the multivariate relationship among samples, while PERMANOVA provided nonparametric multivariate analysis of variance among groups of samples.

\section{RESULTS}

\section{Species occurring in large standing waterbodies}

The complete list of species observed in lakes and reservoirs is found in the Supplementary Tab. 1. A total of 107 species were recorded from the incidence and abundance datasets (Tab. 1), 25 of which were new species records for Cambodia. Conochilus coenobasis (Skorikov 1914), was by far the most abundant and frequent new record found in the abundance and incidence 
datasets, respectively (Fig. 2). This cosmopolitan species has previously been recorded in Thailand and Vietnam, and it was found in both lakes and reservoirs in northern Cambodia during both collection periods of this study. Other relatively abundant new records in the abundance dataset include Lepadella ehrenbergii (Perty 1850) and Monommata longiseta (Müller 1786) that were found in the wet season samples only, the latter in 2 reservoir samples and the former in 1 lake and 1 reservoir sample. $M$. longiseta was also a relatively frequent record in the incidence dataset, found in reservoirs in both the dry and wet season. Another relatively frequent record was Scaridium bostjani Daems \& Dumont 1974 that was found mostly in reservoirs. All three of these species are considered to be cosmopolitan.

Eight of the 107 observed species were not identifiable to species level, and they were considered to be individual taxonomical units in subsequent analyses in this study. Polyartha spp. were by far the most abundant and frequent member of this group, occurring in all four sample sets (Fig. 3). Relatively abundant members in the abundance dataset included Cephalodella spp., Euchlanis spp. and Trichocerca spp., while a relatively frequent member in the incidence dataset was Conochilus sp.

\section{Species diversity in standing waterbodies}

From the incidence data from both seasons, species richness or $D_{\gamma}$ of large standing waterbodies was estimated to be 125 species ( $95 \%$ CI $=111-164$ species). This was not significantly different from that estimated using abundance data (106, 96-129). Neither was significantly different from the regional species richness estimated for samples collected during the dry or wet seasons, or those collected from lakes or reservoirs (Tab. 1). For large standing waterbodies at the local scale, the average species count per site $\left(D_{\alpha}\right)$ was also not significantly different between seasons or between habitat types (Tab. 1). However, $D_{\alpha}$ was significantly higher in the incidence dataset than abundance dataset when all samples or when wet season samples were considered. The pairs of sample sets based on seasons or habitat types also showed no significant difference in dominance index, Berger-Parker index or rotifer density. Furthermore, ANOVA indicated no significant difference among the four sample sets based on the combination of habitat type and season (data not shown). On the other hand, $\beta$ diversity or $D_{\beta}$ yielded results ranging from 3.9 to 5.7 (Tab. 1), indicating substantial difference between local and regional diversity.

The incidence data from 10 ponds sampled during the same field trips (Chean and Meas, 2011; Min et al., 2011) were also analysed using the same metrics where appropriate. $D_{\gamma}$ of ponds was not significantly different between the dry and wet seasons (Tab. 2), nor was it significantly different from that of the large standing waterbodies of this study. $D_{\alpha}$ of pond samples ranged from 15.7-20.3, which was slightly lower than that for large standing waterbodies (20.9-28.4). There was statistically significant difference among these values according to ANOVA $(\mathrm{P}=0.037)$, and posthoc pairwise comparisons indicated that $D_{\alpha}$ of the ponds in the dry season (15.7) was signifi-

Tab. 1. Cumulative species count, regional diversity, local diversity and $\beta$ diversity of rotifers in all samples, dry season and wet season samples of lakes and reservoirs, and lake and reservoir samples of both seasons.

\begin{tabular}{|c|c|c|c|c|c|c|}
\hline Property & Dataset & All & Dry season & Wet season & Lakes & Reservoirs \\
\hline $\mathrm{n}$ & - & 20 & 10 & 10 & 10 & 10 \\
\hline Cumulative species count & $\begin{array}{l}\text { Incidence } \\
\text { Abundance } \\
\text { Combined }\end{array}$ & $\begin{array}{c}103 \\
92 \\
107\end{array}$ & $\begin{array}{l}81 \\
56 \\
82\end{array}$ & $\begin{array}{l}87 \\
77 \\
89\end{array}$ & $\begin{array}{l}78 \\
65 \\
78\end{array}$ & $\begin{array}{l}92 \\
76 \\
92\end{array}$ \\
\hline Regional diversity, $D_{\gamma}^{\circ}$ & $\begin{array}{l}\text { Incidence } \\
\text { (Chao2-bc) } \\
\text { Abundance } \\
\text { (Chao1-bc) }\end{array}$ & $\begin{array}{c}125 \\
(111-164) \\
106 \\
(96-129)\end{array}$ & $\begin{array}{c}124 \\
(99-181) \\
101 \\
(80-151)\end{array}$ & $\begin{array}{c}105 \\
(94-136) \\
91 \\
(81-117)\end{array}$ & $\begin{array}{c}98 \\
(86-130) \\
89 \\
(68-150)\end{array}$ & $\begin{array}{c}117 \\
(102-152) \\
103 \\
(87-144)\end{array}$ \\
\hline \multicolumn{7}{|l|}{ Local diversity ${ }^{\#}$} \\
\hline$D_{\alpha}$ & Incidence & $\frac{24.6}{172}$ & 20.9 & $\frac{28.4}{10.6}$ & 22.9 & 26.4 \\
\hline$D_{\alpha}$ & Abundance & $\underline{17.3}$ & 15.0 & $\underline{19.6}$ & 15.3 & 19.3 \\
\hline Dominance & Abundance & 0.42 & $\begin{array}{l}0.39 \\
0.52\end{array}$ & 0.44 & 0.39 & 0.44 \\
\hline Berger-Parker & Abundance & 0.56 & 0.53 & 0.59 & 0.55 & 0.58 \\
\hline Rotifer density & Abundance & 128 & 122 & 134 & 114 & 143 \\
\hline$\beta$ diversity, $D_{\beta} D \gamma / D \alpha$ & Incidence & 4.95 & 5.69 & 3.87 & 4.41 & 4.13 \\
\hline
\end{tabular}

${ }^{\circ}$ Species richness estimates $\left(\mathrm{D}_{\gamma}\right)$ with their $95 \%$ confidence interval given in parentheses: statistical inferences based on $95 \%$ CI. ${ }^{\#}$ Mean species count per sample $\left(\mathrm{D}_{\alpha}\right)$, dominance index, Berger-Parker index and density (individuals/L) of rotifers: statistical comparisons were conducted using $\mathrm{t}$-test, and also with two-sample paired $\mathrm{t}$-test when comparing sites sampled in the two seasons. There was no significant difference between results from dry and wet seasons, between results from lakes and reservoirs, or between $\mathrm{D}_{\alpha}$ obtained from incidence and abundance datasets except for two exceptions (underlined values). 
cantly lower than that of large standing waterbodies in the wet season (28.4). Furthermore, $t$-test indicated that $D_{\alpha}$ for all pond samples (18.0) was significantly lower than that for all large standing waterbodies (24.6). The relatively low $D_{\alpha}$ of the pond samples yielded relatively high $D_{\beta}$ that ranged from 5.9-11.5, two of these values were about twice as large as those from large standing waterbodies (3.9-5.7).

\section{Shared species and nestedness}

The diversity among sites was examined using counts of shared species and nestedness. When the two seasons were compared for each habitat type, the majority of species were shared between seasons (Tab. 3). However, there were substantial numbers of unshared species, ranging from $20 \%$ (16 unshared vs 65 shared) for 10 large waterbodies in the dry season to as much as $49 \%$ (42 vs 43 ) for 10 ponds in

Tab. 2. Rotifer diversity in 10 ponds found in the same region as the large standing waterbodies examined in this study, as determined using species incidence. The value that was significantly different $(t$-test, $\mathrm{P}=0.05)$ from the corresponding value for large standing waterbodies is underlined. ANOVA and post-hoc pairwise comparisons indicated that $D_{\alpha}$ for ponds in the dry season was significantly lower than that for large standing waterbodies in the wet season (see text).

\begin{tabular}{lccc} 
Properties & All pond samples & Wet season \\
\hline $\mathrm{n}$ & 20 & 10 & 10 \\
Cumulative species count & 120 & 78 & 85 \\
$D_{\gamma}$, Chao2-bc $(95 \% \mathrm{CI})$ & $169(143-221)$ & $166(118-276)$ & $112(97-148)$ \\
$D_{\alpha}$ & $\underline{18.0}$ & 15.7 & 20.3 \\
$D_{\beta}\left(D_{\gamma} / D_{\alpha}\right)$ & 10.5 & 11.5 & 5.9 \\
\hline
\end{tabular}

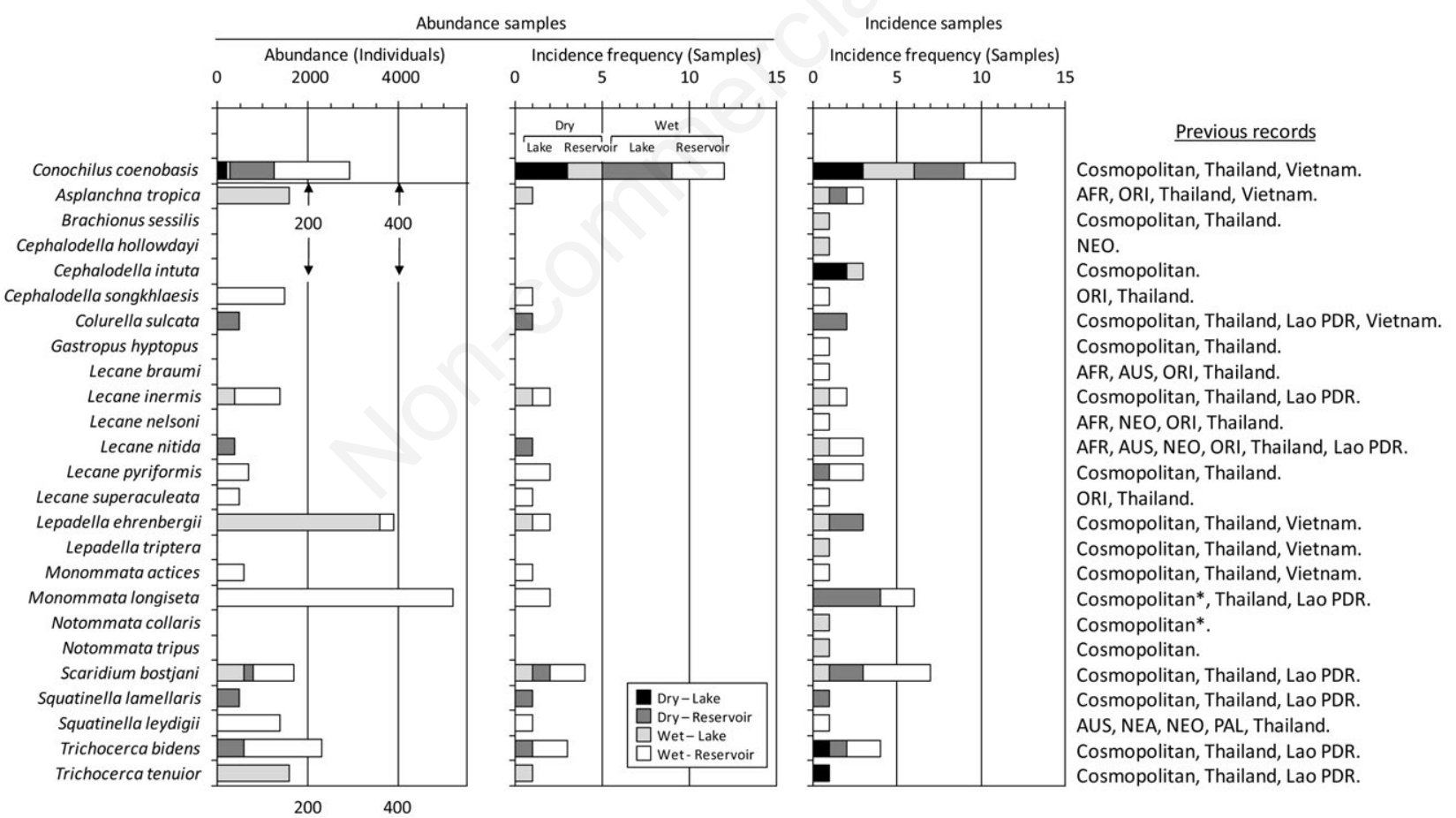

Fig. 2. Occurrence of new records in the samples collected to obtain abundance and incidence data. Sections of each bar represent the distribution of the species shown on the left axis among dry season, wet season, lake and reservoir. As the abundance of $C$. coenobasis is much higher than the other species, there are two sections in the graph for abundance data: i) upper section for $C$. coenobasis only that is associated with the scale indicated on the top axis; ii) lower section for the other species using the scale indicated on the bottom axis. The summary of previous records was determined using Savatenalinton and Segers (2005), Segers (2007), Segers and Sanoamaung (2007), Segers and Savatenalinton (2010), Sa-Ardrit et al. (2013) and Trinh Dang et al. (2013), where AFR, Afrotropical; ANT, Antarctic; AUS, Australian; NEA, Nearctic; NEO, Neotropical; ORI, Oriental; PAC, Pacific; PAL, Palearctic; Cosmopolitan, at least 5 of these 8 biogeographic regions of the world; *, cosmopolitan species not recorded in the Oriental region by Segers (2007). 
the wet season. When large waterbodies and ponds were compared using data from both seasons, dry season only or wet season only, the unshared species ranged from 31\% (32 vs 71) for pond samples across the two seasons to $44 \%$ (36 vs 45) for pond samples in the dry season. Similarly, the unshared species between lakes and reservoirs ranged from $14 \%$ (11 vs 67) for lakes across the two seasons to $47 \%$ (31 vs 35) for reservoirs in the dry season.

Despite the majority of species being shared, the degree of nestedness was typically lower than that expected by chance (Tab. 4). Indeed, the majority of the Z-tansformed scores were negative when random null matrices were constructed using fixed rows and fixed columns constraints or using proportional rows and proportional columns constraints. For each of the two types of null ma- trices, only 2 comparisons revealed significantly lower degree of nestedness in observed NODF than expected by chance. For the fixed-fixed null matrices, these were the NODF value for both types of standing waterbodies across the two seasons and for ponds across the two seasons. For the proportional-proportional null matrices, these were for both types of standing waterbodies in the wet season and for large waterbodies across both seasons.

\section{Relationship to environmental variables}

No clear relationship could be discerned between species abundance and environmental variables measured at the large standing waterbodies. The highest $\rho_{\mathrm{w}}$ correlation value was 0.113 , obtained by combining temperature

Tab. 3. Number of shared species between sample sets determined using incidence data. The parentheses enclose the numbers of unshared species between the samples according to the relevant one of the following orders: (Dry, Wet); (Large waterbodies, Ponds); (Lakes, Reservoirs).

\begin{tabular}{|c|c|c|c|c|c|}
\hline & \multirow{3}{*}{$\begin{array}{c}\text { Between seasons } \\
\text { (Dry vs Wet) }\end{array}$} & \multirow[b]{3}{*}{ n } & \multicolumn{3}{|c|}{ Between samples ${ }^{\circ}$} \\
\hline & & & \multirow{2}{*}{$\begin{array}{l}\text { Both seasons } \\
2 \times(20 \text { or } 10)\end{array}$} & \multirow{2}{*}{$\begin{array}{c}\text { Dry } \\
2 \times(10 \text { or } 5)\end{array}$} & \multirow{2}{*}{$\begin{array}{c}\text { Wet } \\
2 \times(10 \text { or } 5)\end{array}$} \\
\hline & & & & & \\
\hline All samples & $82(32,38)$ & $2 \times 20$ & - & - & - \\
\hline Large waterbodies & $65(16,22)$ & $2 \times 10$ & $71(49,32)$ & $45(33,36)$ & $52(33,35)$ \\
\hline Ponds & $43(35,42)$ & $2 \times 10$ & & & \\
\hline Lakes & $36(14,28)$ & $2 \times 5$ & $67(11,25)$ & $35(15,31)$ & $49(15,23)$ \\
\hline Reservoirs & $46(20,26)$ & $2 \times 5$ & & & \\
\hline
\end{tabular}

${ }^{\circ}$ Category of large waterbodies and ponds has twice as many samples as lakes and reservoirs. Dry, dry season; Wet, wet season.

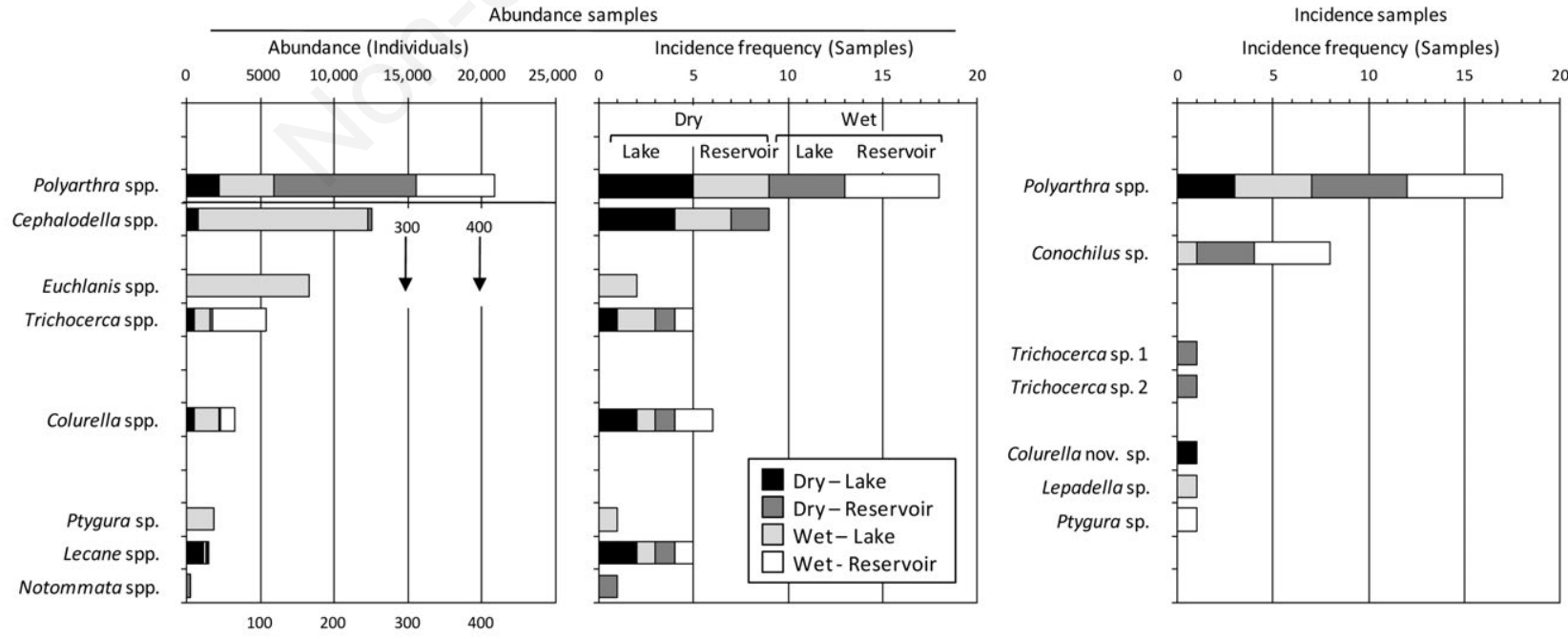

Fig. 3. Occurrence of taxa not identifiable to species in the samples collected to obtain abundance and incidence data. Sections of each bar represent the distribution of the taxon shown on the left axis among dry season, wet season, lake and reservoir is shown. As the abundance of Polyarthra spp. is much higher than the other taxa, there are two sections in the graph for abundance data: i) upper section for Polyarthra spp. only that is associated with the scale indicated on the top axis; ii) section for the other taxa using the scale indicated on the bottom axis. 
and $\mathrm{pH}$ data to determine the abiotic dissimilarity matrix. This value was higher than the highest obtained with a single environmental variable ( 0.068 , temperature). These low positive values indicated that the match between patterns was closer to random than a positively correlated relationship. The analysis was also conducted on four different sample sets that considered data from only the dry season, wet season, lake samples and reservoir samples, respectively. The highest $\rho_{\mathrm{w}}$ values from analysis of these sample sets were also small and ranged from 0.06 to 0.26 . Non-metric multidimensional scaling (nMDS) indicated that clusters of samples based on season were more clearly discerned with the environmental variables than with species abundance or species incidence (Fig. 4).
PERMANOVA results indicated that there were significant differences between the two seasons and among the four combinations of habitat types and seasons according to environmental measurements, while there was significant difference only between the two seasons according to species abundance (Tab. 5).

As PERMANOVA of species incidence data from large standing waterbodies showed significant difference between the 2 seasons, between the two habitat types and among the four combinations of habitat types and seasons, $\rho_{\mathrm{w}}$ was determined between species incidence and the different combinations of environmental variables. The highest $\rho_{\mathrm{w}}$ values observed was 0.166 , obtained using $\mathrm{pH}$ data only. Including any of the other four environmental vari-

Tab. 4. The assessment of nestedness in sample sets using NODF and its Z-transformed score. Significant difference from null matrices is underlined.

\begin{tabular}{|c|c|c|c|c|c|c|}
\hline \multirow[t]{2}{*}{ Sample set } & \multirow[t]{2}{*}{$\mathrm{n}$} & \multirow[t]{2}{*}{ NODF } & \multicolumn{2}{|c|}{ FF } & \multicolumn{2}{|c|}{ PP } \\
\hline & & & $\mathbf{Z}$ & $\mathbf{P}$ & $\mathrm{Z}$ & $\mathbf{P}$ \\
\hline \multicolumn{7}{|l|}{ Standing waterbodies } \\
\hline All & 40 & 23.19 & -2.34 & $\underline{0.010}$ & -1.51 & 0.066 \\
\hline Dry season & 20 & 14.70 & -0.72 & $\overline{0.235}$ & -0.89 & 0.186 \\
\hline Wet season & 20 & 18.05 & -1.38 & 0.083 & -1.97 & $\underline{0.024}$ \\
\hline \multicolumn{3}{|l|}{ Large waterbodies } & +2 & & & \\
\hline All & 20 & 16.42 & -0.40 & 0.343 & -1.75 & 0.040 \\
\hline Dry season & 10 & 10.06 & 0.63 & 0.265 & -0.68 & $\overline{0.248}$ \\
\hline Wet season & 10 & 13.66 & 0.16 & 0.436 & -1.14 & 0.128 \\
\hline Lakes & 10 & 10.51 & -0.28 & 0.389 & -1.14 & 0.127 \\
\hline Reservoirs & 10 & 13.84 & -1.31 & 0.095 & -1.39 & 0.083 \\
\hline \multicolumn{7}{|l|}{ Ponds } \\
\hline All & 20 & 14.05 & -2.51 & 0.006 & -1.23 & 0.109 \\
\hline Dry season & 10 & 7.63 & -0.46 & 0.322 & -0.35 & 0.362 \\
\hline Wet season & 10 & 9.25 & -0.77 & 0.220 & -0.75 & 0.227 \\
\hline
\end{tabular}

FF, fixed rows and columns; PP, proportional rows and columns.
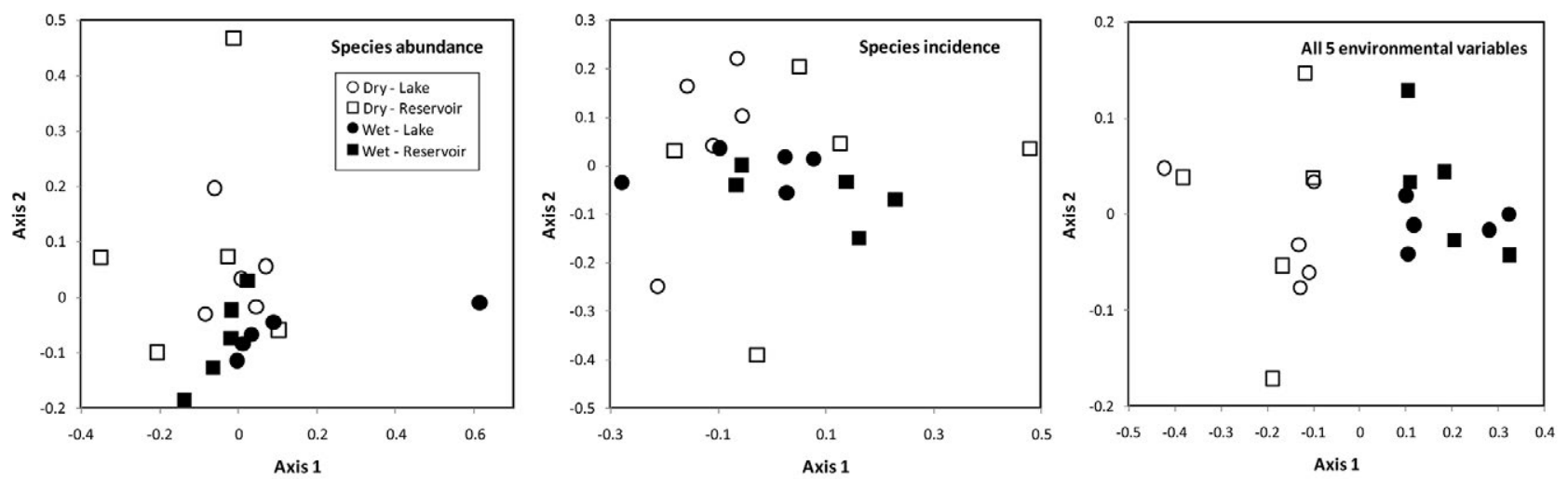

Fig. 4. Non-metric multidimensional scaling of species composition and 5 environmental variables determined for the 20 samples of large standing waterbodies of this study. The 5 environmental variables considered in this analysis were conductivity, dissolved oxygen, $\mathrm{pH}$, temperature and turbidity. 
ables decreased the correlation with biotic properties. Similarly, $\rho_{\mathrm{w}}$ remained low when analysing the large standing waterbodies together with ponds. The highest $\rho_{w}$ value was 0.145 , which was obtained by combining turbidity and $\mathrm{pH}$ data, with turbidity alone providing $\rho_{\mathrm{w}}$ of 0.119 . Given the observed separation of sites by nMDS and PERMANOVA, data from individual seasons and habitat types were also examined for all standing waterbodies. The best $\rho_{\mathrm{w}}$ obtained was from the wet season samples, in which combining the data for turbidity and conductivity yielded $\rho_{\mathrm{w}}$ of 0.358 (Tab. 6), and the corresponding nMDS is shown on Fig. 5. The $\rho_{\mathrm{w}}$ value was not reduced when $\mathrm{pH}$ and temperature data were added to the analysis.

\section{Comparison with previous studies}

The species richness estimation from the combined incidence data from all studies to date, totaling 10 reports, was 403 species with $95 \%$ CI of 386 to 432 . These reports include the present study, Bērziņš (1973), Davidson et al. (2006), Vongsombath et al. (2009), Meas and Sanoamuang (2010), Min et al. (2011), Sor (2011), Min (2013), and two unpublished reports (Prouch, 2010; Chean and Meas, 2011).

Compared to other habitat types, rivers, seasonal wetlands and permanent wetlands had the higher species richness, estimated to be 234,256 and 259 species with $95 \%$ confidence interval of 190-328, 213-338 and 230-316, re-

Tab. 5. PERMANOVA of sample sets using species abundance, species incidence, all environmental variables measured and the relevant combination of environment variables yielding the highest $\rho_{\mathrm{w}}$. The results shown are the probability that there is no difference between the sample sets being compared.

\begin{tabular}{|c|c|c|c|c|c|}
\hline & \multirow[b]{2}{*}{$\mathrm{n}$} & \multicolumn{2}{|c|}{ Species } & \multicolumn{2}{|c|}{ Environmental variables } \\
\hline & & Abundance & Incidence & Measured $^{\circ}$ & Relevant ${ }^{\#}$ \\
\hline \multicolumn{6}{|l|}{ Large standing waterbodies } \\
\hline Dry $v s$ Wet & $2 \times 10$ & 0.013 & 0.028 & $<0.001$ & $<0.001$ \\
\hline Lake $v s$ Reservoir & $2 \times 10$ & 0.672 & 0.049 & 0.596 & 0.434 \\
\hline Habitat-season combinations & $4 \times 5$ & 0.156 & 0.046 & $<0.001$ & $<0.001$ \\
\hline \multicolumn{6}{|c|}{ Ponds (only incidence data available) } \\
\hline Dry $v s$ Wet & $2 \times 10$ & - & $<0.001$ & 0.250 & - \\
\hline \multicolumn{6}{|c|}{ All standing waterbodies (only incidence data available) } \\
\hline Dry $v s$ Wet & $2 \times 20$ & - & $<0.001$ & $<0.001$ & $<0.001$ \\
\hline Large $v s$ Ponds & $2 \times 20$ & - & $<0.001$ & $<0.001$ & 0.004 \\
\hline Habitat-season combinations & $4 \times 10$ & - & $<0.001$ & $<0.001$ & $<0.001$ \\
\hline \multicolumn{6}{|c|}{ All standing waterbodies in wet season (only incidence data available) } \\
\hline Large $v s$ Ponds & $2 \times 10$ & - & $<0.001$ & $<0.001$ & 0.001 \\
\hline
\end{tabular}

${ }^{\circ}$ Conductivity, dissolved oxygen, $\mathrm{pH}$, temperature, turbidity; for comparisons of ponds or all standing waterbodies, dissolved oxygen data were missing

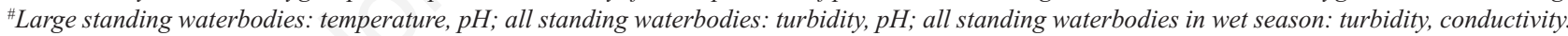

Tab. 6. Combination of environmental variables providing the highest $\rho_{\mathrm{w}}$ (weighted Spearman rank correlation coefficient) between biotic and abiotic dissimilarity matrices of all standing waterbodies in the wet season. The biotic dissimilarity matrix was based on species incidence and Bray-Curtis similarity, while the abiotic matrix was based on Euclidean distance.

\begin{tabular}{lcc} 
Number of variables & Environment variable(s) & $\rho_{w}$ \\
\hline 1 & Turbidity & 0.227 \\
& Conductivity & 0.086 \\
\hline 2 & Turbidity, conductivity & 0.358 \\
& Turbidity, $\mathrm{pH}$ & 0.301 \\
\hline 3 & Turbidity, conductivity, pH & 0.358 \\
& Turbidity, conductivity, temperature & 0.358 \\
& Turbidity, $\mathrm{pH}$, temperature & 0.301 \\
\hline 4 & Turbidity, conductivity, $\mathrm{pH}$, temperature & 0.358 \\
\hline
\end{tabular}


spectively. The species richness of these three habitat types was significantly higher than all of the other habitats except ponds (Fig. 6). Streams (76 species) had significantly lower species richness than ponds (180), canals (133), reservoirs (130), floodplains (128), and lakes (109), but not lower than rice fields (97) according to $95 \%$ CI.

\section{DISCUSSION}

At the time of this study (2010), the total rotifer species recorded in Cambodia was 240 excluding the new records and the unidentifiable species of this study. After reviewing all recent literatures and including the results of the present study, there now appears to be a total of 306 valid species of Monogononta rotifers on record for Cambodia, excluding sub species and variants. This total number of reported taxa has differed among recent reports because the unpub- lished studies of Prouch (2010) and Chean and Meas (2011) were not always included. There was also some confusion from the identification of synonymous species and the use of outdated taxonomical key books and literatures. Examples of those species are the Diurella spp. and Schizocerca diversicornis Daday, 1883, recorded by Davidson et al. (2006) and Vongsambath et al. (2009), which were systematically classified as Trichocerca spp. and Brachionus diversicornis (Daday 1883), respectively, by Segers (2007). Finally, some species of Bdelloidea such as Philodina spp. and Rotaria spp. found by Davidson et al. (2006) and Vongsambath et al. (2009) were sometimes included in previous compilations, whereas this study only considered Monogononta rotifers.

This study found 25 new species records for Cambodia (Supplementary Tab. 1), of which Conochilus coenobasis (Skorikov, 1914) and Gastropus hyptopus (Ehrenberg,
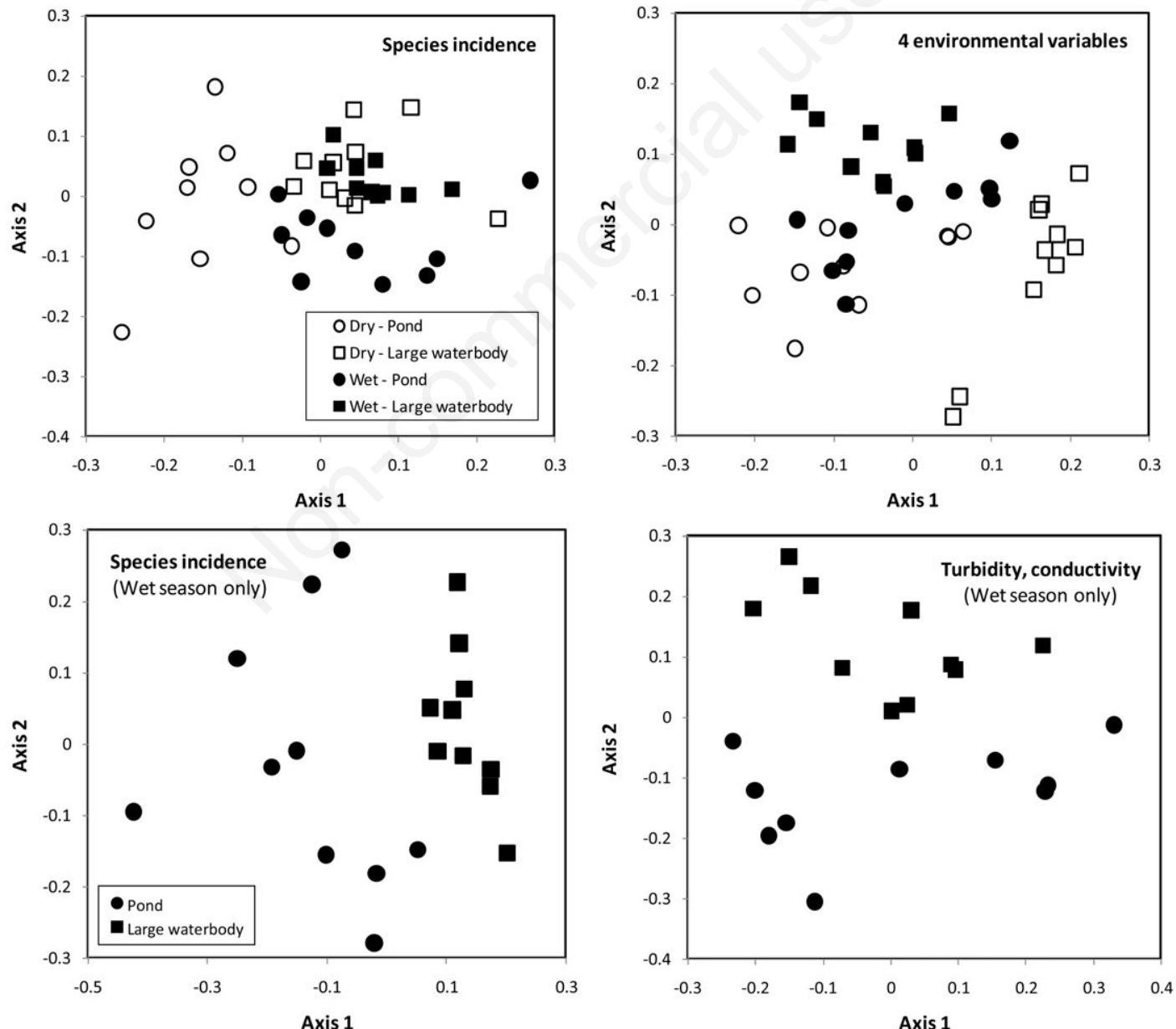

Fig. 5. Non-metric multidimensional scaling of species incidence and 4 environmental variables determined for ponds (Chean and Meas, 2011; Min et al., 2011) and large standing waterbodies (this study). Top row shows all samples, while bottom row show the wet season samples only that have the highest correlation $\left(\rho_{\mathrm{w}}=0.358\right)$ to the environmental variables measured. The four environmental variables considered in this analysis were conductivity, $\mathrm{pH}$, temperature and turbidity. 
1838) represented two new genera in the record. Among the 25 , there were some records that concern rare species or species that are not commonly found, such as Brachionus sessilis Varga, 1951, Cephalodella hollowdayi Koste, 1986 and Lecane nelsoni Segers, 1994. In contrast, C. coenobasis was very common in both incidence and abundance data, occurring in both lakes and reservoirs in the dry and wet seasons. Even though $C$. coenobasis is newly recorded from this study, it was considered cosmopolitan by Segers (2007). It is therefore surprising that this species had not been previously recorded from Cambodia while it and other members of the same genus have previously been found in neighboring countries (Sanoamuang et al., 1995; Savatenalinton and Segers, 2005; Segers and Sanoamuang, 2007; Sa-Ardrit et al., 2013; Trinh Dang et al., 2013), Europe (Koste and Hollowday, 1993; Bonecker and Lansac-Tôha, 1996) and China (Wen et al., 2011). From both abundance and incidence data, Polyarthra spp. were the most frequently encountered taxa found across both habitat types and both seasons, while the Lepadella sp., Ptygura sp. and Notommata sp. were the least frequently found of the unidentifiable species encountered (Fig. 3). The case of Polyarthra spp. is the most difficult because the species-level taxa in this genus are morphologically similar and extremely difficult to identify. This can explain why some studies record only one Polyarthra sp. (Davidson et al., 2006), while Meas and Sanoamoang (2010) and Min (2013) reported only $P$. vulgaris, and Chean and Meas (2011) reported only P. dolichoptera. In contrast, Vongsambath et al. (2009) reported P. vulgaris and listed P. mira, which was probably a lapsus regarding Hexarthra mira.

From the review of past reports, the total number of unidentified taxa has reached 60 . Some of these taxa were considered to be possible new species to science, such Conochilus sp., Ptygura sp. and Colurella sp. of Sor (2011), and Cephalodella sp. 2, Lepadella sp. 3, Lecane sp. 2, and Notommata sp. 6 of Min (2013). All of these and some of the other unidentified taxa could be possibly identified to species level if a scanning electron microscopy (SEM) were available to analyze the trophi following the method of Segers (1993) and De Smet (1998). Alternatively, recent advances in DNA analyses could be used to discriminate species (Gomez, 2005). These techniques would also be helpful for taxonomic analysis of unidentified taxa elsewhere in Southeast Asia, including those belonging to four genera in Lao PDR (Segers and Sanoamuang, 2007) and the genus Tetrasiphon in Vietnam (Trinh Dang et al., 2013).

The species abundance data of the present study provided other measurements of diversity, including domi-

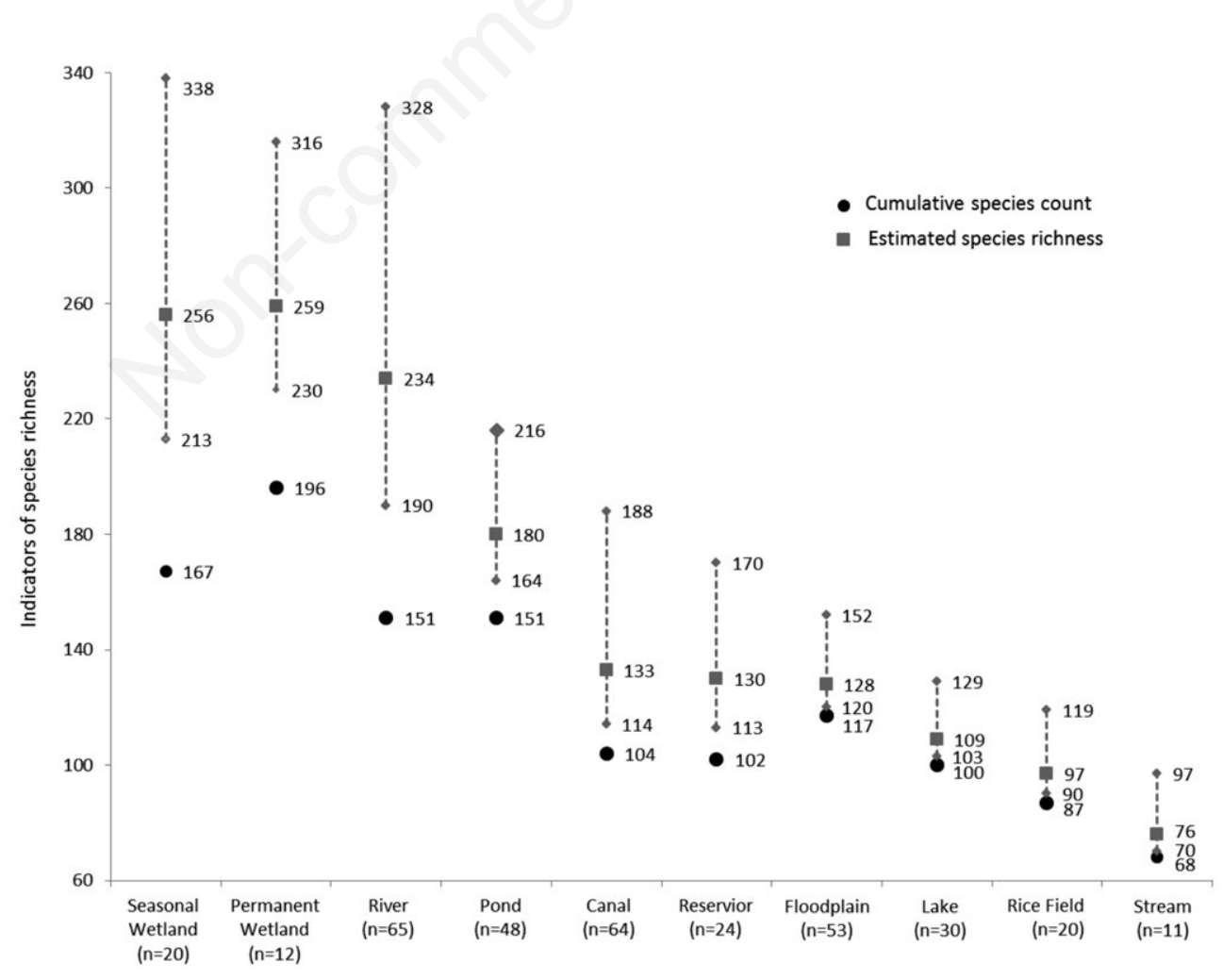

Fig. 6. Cumulative species count and species richness in each type of habitat examined in this and past studies. The error bars show the $95 \% \mathrm{CI}$ of species richness as determined by Chao2-bc for incidence data, and the corresponding sample size is provided on the $\mathrm{x}$-axis. 
nance and rotifer density, but were based on species found in subsamples of a smaller volume collected from the sites. The results did not reveal statistically significant differences among the sample sets based on two types of large standing waterbodies, seasons or both. Furthermore, neither incidence nor abundance data revealed statistical difference in species richness. The lack of difference between seasons seems to contradict the earlier findings of Meas and Sanoamuang (2010) that higher species richness could be found in the late wet season (October) compared to the early dry season (December) and the early wet season (June). The results of the current study and those of Chean and Meas (2011) and Min et al. (2011) could be considered more reliable because exactly the same localities were sampled in the two seasons (April vs November), but the conclusion is limited to lakes, reservoirs and ponds. A lack of seasonal patterns in species richness could be due to a large number of rotifer species showing no seasonal preferences (Wallace et al., 2006). The finding would be more conclusive if data from both seasons were available from all studies to date. It also appears necessary to collect more samples in October to verify the significantly higher species richness detected by Meas and Sanoamuang (2010).

The large difference between regional species richness $\left(D_{\gamma}\right)$ and local species richness $\left(D_{\alpha}\right)$ indicates relatively large $\beta$ diversity $\left(D_{\beta}\right)$, the potential components of which have been the subject of substantial debate and discussion (Anderson et al., 2011). Although nestedness has often been discussed in the partitioning of $D_{\beta}$ into independent components (Baselga, 2010; Carvalho et al., 2013), the NODF metric indicated that the degree of nestedness in rotifer communities among standing waterbodies is typically lower than that expected by chance. An attempt was also made to use multivariate analysis to determine whether certain environmental variables are contributing substantially to species composition based on abundance or incidence data. However, the environmental variables measured, namely conductivity, dissolved oxygen, $\mathrm{pH}$, temperature and turbidity of the water, could only account for a small portion of the diversity observed among sites. One explanation is that none of the environmental variables measured greatly influences species composition. Another possible explanation is that the population of rotifer species in samples is the result of the life history of individual rotifers, which cannot be represented simply by environmental measurements made at the time of sampling. It therefore appears necessary for future work to assess temporal patterns of biotic variables (such as predators and prey) and environmental variables (include more variables, such as organic carbon, total phosphate, micronutrients and pollutants), along with biogeographic variables (such as hydrologic connectivity, altitude, geographic coordinates).
The high level of $\beta$ diversity was reflected by the relatively high levels of unshared species between sample sets. For example, as much as $49 \%$ of the species found in ponds in the wet season were not detected in ponds in the dry season. Distinctive rotifer communities were also revealed among sample sets by nMDS and PERMANOVA analyses. Both nMDS and PERMANOVA appeared more effective for distinguishing between the dry and wet seasons and between large standing waterbodies and ponds, than between lakes and reservoirs. As each habitat type and season showed unique collections of species, they all contribute to the overall biodiversity of rotifers in the standing waterbodies of Cambodia and should be considered in discussions of biodiversity conservation. Similar to the findings of Hamerlík et al. (2014) on macroinvertebrates among mountain ponds and lakes, there is evidence that ponds in northern Cambodia have significantly lower local richness $\left(D_{\alpha}\right)$ than large standing waterbodies but similar regional species richness $\left(D_{\gamma}\right)$. The statistical difference was predominantly due to the relatively low $D_{\alpha}$, and consequentially relatively high $D_{\beta}$, in ponds in the dry season compared to that in large standing waterbodies in the wet season. It would appear that the higher degree of isolation, particularly in the dry season, and the smaller total volume of ponds yield relatively low local species richness, as could be expected from ecological concepts based on hydrological connectivity (Ward et al., 1999) and patch dynamics (Townsend, 1989).

\section{CONCLUSIONS}

Rivers and ponds have been found to collectively support high rotifer richness and this could be partly due to the many number of survey of rivers (Bērziñš, 1973; Davidson et al., 2006; Vongsombath et al., 2009; Meas and Sanoamuang, 2010) and ponds (Meas and Sanoamuang, 2010; Segers et al., 2010; Chean and Meas, 2011; Min et al., 2011). Remarkably, a single study of seasonal and permanent wetlands, comprised of 20 and 12 sample sites, respectively, found equivalently high species richness in these habitats in protected areas (Min, 2013). Protected areas could be expected to support high interaction between all fauna, such as crustaceans, frogs and birds, which is capable of facilitating rotifer movement (Wallace et al., 2006), and there should be less pollution and less human activities that may affect rotifer species. The presence of water over the year in sample sites with high habitat complexity, especially in the permanent wetlands, could also be another advantage for rotifer species, particularly the sessile rotifers. In the case of rivers, high species richness from the studies of Davidson et al. (2006), Vongsambath et al. (2009) and Meas and Sanoamuang (2010), would suggest that rapidly flowing water could also support many species, perhaps by the provision of additional nutrients or food. 
This study combined all existing data, providing a general picture of rotifers studied in Cambodia to date. Even though the record of valid species has reached 306, it is still lower than the 398 species on record in Thailand (Sa-Ardrit et al., 2013) but higher than the 174 records in Vietnam (Trinh Dang et al., 2013). New country records are still being found, and the number of unidentifiable and possibly new species has also increased. There remain large regions of the country that have not been thoroughly surveyed, and the comparison of rotifer species occurrence between regions, habitat types or seasons would be much better if the number of surveys is relatively similar for each habitat type and if the sampling periods are more consistent.

\section{ACKNOWLEDGMENTS}

This work was supported by the Centre for Biodiversity Conservation (CBC) and the Department of Biology, Faculty of Science, Royal University of Phnom Penh (RUPP).

\section{REFERENCES}

Almeida-Neto M, Ulrich W, 2011. A straightforward computational approach for measuring nestedness using quantitative matrices. Environ. Modell. Software 26:173-178.

Anderson MJ, Crist TO, Chase JM, Vellend M, Inouye BD, Freestone AL, Sanders NJ, Cornell HV, Comita LS, Davies KF, Harrison SP, Kraft NJB, Stegen JC, Swenson NG, 2011. Navigating the multiple meanings of $\beta$ diversity: a roadmap for the practicing ecologist. Ecol. Lett. 14:19-28.

Baselga A, 2010. Partitioning the turnover and nestedness components of beta diversity. Global Ecol. Biogeogr. 19:134-143.

Bērziņš B, 1973. Some Rotifers from Cambodia. Hydrobiologia 41:453-459.

Bonecker C, Lansac-Tôha F, 1996. Community structure of rotifers in two environments of the upper River Paraná floodplain (MS)-Brazil. Hydrobiologia 325:137-150.

Carvalho JC, Cardoso P, Borges PAV, Schmera D, Podani J, 2013. Measuring fractions of beta diversity and their relationships to nestedness: a theoretical and empirical comparison of novel approaches. Oikos 122:825-834.

Chao A, Shen TJ, 2006. Program SPADE (Species Prediction And Diversity Estimation): Program and User's Guide. National Tsing Hua University and National Chung Hsing University, Taiwan. Available from: http://chao.stat.nthu.edu.tw.

Chean K, Meas S, 2011. Species richness of rotifers in pond samples in the late rainy season in Kratie, Stung Treng and Ratanakiri Provinces. Centre for Biodiversity Conservation, Royal University of Phnom Penh.

Clarke KR, Ainsworth M, 1993. A method of linking multivariate community structure to environmental variables. Mar. Ecol. Prog. Ser. 92:205-219.

Davidson PS, Kunpradid T, Peerapornisal Y, Nguyen TML, Pathoumthong B, Vongsambath C, Pham AD, 2006. Biomonitoring of the lower Mekong River and selected tributaries. MRC Technical Paper No.13. Vietiane, Lao PDR.

Gomez A, 2005. Molecular ecology of rotifers: from population differentiation to speciation. Hydrobiologia 546:83-99.
Hamerlík L, Svitok M, Novikmec M, Očadlík M, Bitušík P, 2014. Local, among-site, and regional diversity patterns of benthic macroinvertebrates in high altitude waterbodies: do ponds differ from lakes? Hydrobiologia 723:41-52.

Hammer Ø, Harper DAT, Ryan PD, 2001. PAST: Paleontological Statistics Software Package for Education and Data Analysis. Palaeontologia Electronica 4(1):9pp.

Koste W, 1978. [Rotatoria: die Rädertiere Mitteleuropas begründet von Max Voigt. Monogononta].[Book in German]. Gebrüder Borntraeger: 673 pp

Koste W, 1990. [Zur Kenntnis der Rädertierfauna des KindaStausees in Zentral-Burma (Aschelminthes: Rotatoria)].[Article in German]. Osnabrücker Naturwiss. Mitt. 16:83-110.

Koste W, Hollowday ED, 1993. A short history of western European rotifer research. Hydrobiologia 255:557-572.

Meas S, Sanoamuang L, 2010. New records of rotifer fauna in the Cambodia Mekong River Basin. Cambodian J. Natl. Hist. 2010:48-62.

Meas S, Sor R, (2013). New records of rotifer fauna in the upper Cambodian Mekong River Basin. Int. J. Environ. Rural Dev. (In press).

Min M, 2013. Rotifer Community in wetlands in Lumphat wildlife sanctuary. Msc Thesis, Royal University of Phnom Penh.

Min M, Wong KKY, Seanghun M, 2011. Rotifer fauna in pond samples from the upper Cambodian Mekong River Basin. Cambodian J. Natl. Hist. 2011:14-22.

Nogrady T, Pourriot R, Segers H, 1995. Rotifera, 3: Notommatidae and the Scaridiidae. SPB Academic: $248 \mathrm{pp}$.

Nogrady T, Segers H, 2002. Rotifera, 6: Asplanchnidae, Gastropodidae, Lindiidae, Microcodidae, Synchaetidae, Trochosphaeridae and Filinia. Backhuys: 264 pp.

Prouch T, 2010. Species diversity of rotifers in Trapeangthmor reservoir in Phnom Srok district, Banteay Meanchey Province. BSc Thesis, Royal University of Phnom Penh.

Sa-Ardrit P, Pholpunthin P, Segers H, 2013. A checklist of the freshwater rotifer fauna of Thailand (Rotifera, Monogononta, Bdelloidea). J. Limnol. 72:361-375.

Sanoamuang L, Segers H, Dumont HJ 1995. Additions to the rotifer fauna of south-east Asia: new and rare species from north-east Thailand. Hydrobiologia 313/314:35-45.

Savatenalinton S, Segers H, 2005. Rotifers from Kalasin province, northeast Thailand, with notes on new and rare species. Zoolocial. Stud. 44:361-367.

Segers H, 1993. Rotifera of some lakes in the floodplain of the River Niger (Imo State, Nigeria) I . New species and other taxonomic considerations. Hydrobiologia 250:39-61.

Segers H, 1994. On four new tropical and subtropical Lecane (Lecanidae, Monogononta, Rotifera). Hydrobiologia 287:243-249.

Segers H, 1995. Rotifera, 2: the Lecanidae (Monogononta). SPB Academic Publ.: 226 pp.

Segers H, 2001. Zoogeography of the Southeast Asian Rotifera. Hydrobiologia 446/447:233-246.

Segers H, 2007. Annotated checklist of the rotifers (Phylum Rotifera), with notes on nomenclature, taxonomy and distribution. Zootaxa 1564:1-104.

Segers H, Meksuwan P, Sanoamuang L, 2010. New records of sessile rotifers (Phylum Rotifera: Flosculariacea, Collothecacea ) from Southeast Asia. Belg. J. Zool. 140:235-240.

Segers H, Sanoamuang L, 2007. Note on a highly diverse rotifer 
assemblage (Rotifera: Monogononta) in a Laotian rice paddy and adjacent pond. Int. Rev. Hydrobiol. 92:640-646.

Segers H, Savatenalinton S, 2010. A critical re-evaluation of the Lecanidae (Rotifera: Monogononta) of Thailand, with description of a new species. Int. Rev. Hydrobiol. 95:343-351.

De Smet WH, 1998. Preparation of rotifer trophi for light and scanning electron microscopy. Hydrobiologia 387/388:117-121.

De Smet WH, Pourriot R, 1997. Rotifera, 5: the Dicranophoridae (Monogononta). Backhuys: 340 pp.

Sor R, 2011. Comparison of the rotifer fauna between lakes and reservoirs in the upper part of the Cambodian Mekong River basin. Msc Thesis, Royal University of Phnom Penh.

Townsend CR, 1989. The patch dynamics concept of stream community ecology. J. N. A. Benthol. Soc. 8:36-50.

Trinh Dang M, Segers H, Sanoamuang L, 2013. Rotifers from Thuy Tien Lake and Nhu Y river in central Vietnam, with a description of Ploesoma asiaticum new species (Rotifera: Monogononta). J. Limnol. 72:376-386.
Tuyor JB, Segers H, 1999. Contribution to the knowledge of the Philippine freshwater zooplankton: new records of monogonont Rotifera. Int. Rev. Hydrobiol. 84:175-180.

Vongsombath C, Pham AD, Nguyen TML, Kunpradid T, Davidson SP, Peerapornisal Y, Sok K, Meng M, 2009. Report on the 2006 biomonitoring survey of the lower Mekong River and selected tributaries. MRC Technical Paper No. 22. Vietiane, Lao PDR.

Wallace RL, Snell TW, Ricci C, Nogrady T, 2006. Rotifera biology, ecology and systematics, 2nd ed. Backhuys: 299 pp.

Ward JV, Tockner K, Schiemer F, 1999. Biodiversity of floodplain river ecosystems: Ecotones and connectivity. Regul. Riv. Res. Manage. 15:125-139.

Wen XL, Xi YL, Qian FP, Zhang G, Xiang XL, 2011. Comparative analysis of rotifer community structure in five subtropical shallow lakes in East China: role of physical and chemical conditions. Hydrobiologia 661:303-316. 